\title{
Epidemiological study of Congenital Hydrocephalus in Sohag Governorate
}

Magda M. Ali and M.A. Abdelaal

Departments of Community Medicine and Neurosurgery, Sohag Faculty of Medicine, Sohag University, Sohag, Egypt.

\begin{abstract}
Introduction: Hydrocephalus is defined as the extra cerebral accumulation of water, the commonest neurological anomalies, one of leading causes of morbidity and mortality in infants worldwide.
\end{abstract}

Objective: To study the epidemiology, evaluate management and prevention of Congenital Hydrocephalus.

Methods: A cross sectional study was conducted for infants from Sohag University and Insurance hospitals from March 2014 to December 2014. All recruited infants after clinical evaluation and investigation to ensure the diagnosis, were interviewed assessing socio-demographic conditions, risk factors then data are statistically analysed.

Results: In our study including 240 hydrocephalic infants and 600 non hydrocephalic, the estimated incidence of hydrocephalus was 6.76/1000 living births. Significant risk factors were identified: uniparity (53.3\%), age of the mother <20 years at conception (25\%), maternal diabetes $(13.8 \%)$, fever and common cold $(32.1 \%)$, exposure to pollutants, irradiation $(15.1 \%)$ and $(13.3 \%)$ respectively. Consanguinity was present in $58 \%$, family history was detected in $20.8 \%$, drugs intake in $63.8 \%$, fathers above 50 years at time of conception was detected in $30.4 \%$, of them $(85.28 \%)$ were non professionals, no antenatal care $(51.7 \%)$, polyhydramnios $(7.5 \%)$, oligohydramnios (7.1\%), early vaginal bleeding $(14.2 \%)$, preeclampsia $(7.5 \%)$, twins was recorded $(7.9 \%)$, breech presentation in $(12.9 \%)$. Congenital hydrocephalus was treated by shunt operation in 230 infants (85\%), and prognosis was good in $70 \%$.

Conclusions: Important risk factors have been identified, strongly associated with the development of congenital hydrocephalus in infants. Improvement antenatal care, socio-demographic conditions and adopted fortification of the staple food are needed to our locality.

Key words: Epidemiology, congenital hydrocephalus, management.

\section{Introduction}

Congenital hydrocephalus (from Greek hydro-, meaning "water", and ceph, meaning "head") is a medical condition usually congenital condition and which an abnormal accumulation of cerebrospinal fluid in the cerebral venticle(1).Morbidity and mortality rates vary internationally but in General and rising throughout the world, the highest incidence rates are found in Africa, Asia. Prevalence was reported (0.5-2) per 1000 pregnancies world wide, with variations in prevalence ranging from (0.2-10) per 1000 in specific geographical locations. More than $(300,000)$ cases are estimated to occur world wide each year, in Saudi Arabia, a birth prevalence of 1.6 per 1000 live births, in Egypt high prevalence 3.76.96/1000(2).

The increase did not continue in the following years, probably due to the improved prenatal and perinatal care of 
these high-risk infants (3).Management was described in (1923) by use of endoscopic perforation of the floor of the third ventricle, endoscopic third ventriculostomy (ETV), but it was not a success because of technical problems and complications and for many decades ETV was not used(4).

Around (1960) the use of ventricular shunts became more common, as materials and techniques had improved, the use of modern shunts resulted in a reduction in mortality from $50 \%$ to about $10 \%$ during the last decade, ventriculostomy has once again been used more frequently as an alternative to shunt treatment, prevalence from 1979 to 1986 and this was thought to be due to the enhanced survival of infants born very preterm with a high risk of developing hydrocephalus with intraventricular haemorrhage as the cause(5)

Prevention was done by the Folic acid supplementation. The recommended daily dose of folic acid is $0.4 \mathrm{mg}$, surveys of hydrocephalus must be done in every country and even in different regions of same country to provide prevalence of hydrocephalus(6). The crude prevalence of infantile hydrocephalus was0.57per 1000 neonatal survivors, the gestational age prevalence was 21-65 per 1000 severe preterm infants, 1.99 per 1000 moderately preterm, and 0.36 per 1000 infants born at term(7). In Saudia Arabia, a prospective study from 19961997 reported a birth prevalence of 1.6 per 1000 live births, in children with hydrocephalus associated with abnormal folate intake or metabolism is known to have a role in the pathogenesis of hydrocephalu(8).

\section{Aim of the work:}

to study the epidemiology, evaluate post natal management and prevention of Congenital Hydrocephalus .

\section{Subjects and Methods: \\ Type of the study:}

A cross sectional study was conducted for infants in outpatient clinics and inpatients from Sohag University and health insurance hospitals as these hospitals received almost all cases from Sohag Governorate. The field work and data collection lasted from March 2014 to December 2014.

\section{Sample size justification:}

Number of hydrocephalic infants and control ones were calculated using computerized method (open Epi, version 3 open source calculator proportion)

$\mathrm{N}=$ the desired sample size when population is more than 10.000 .

$\mathrm{P}=$ Prevalence of hydrocephalus (7.97 in developing countries per 1000.

So the calculated sample size was 240 infants with hydrocephalus and 600 control infants.

\section{Target Patient:}

The study population comprised of 240 infants with hydrocephalus from department of neurosurgery, Sohag faculty of medicine, Sohag University and crescent health insurance hospital as these hospitals received near all cases from Sohag governorate. For the purpose of comparison we aimed at recruiting hydrocephalic and non hydrocephalic infants attending the outpatient clinics and inpatients of these hospitals during the period from march 2014 to February 2015

Inclusion criteria for patients were: Infants of congenital hydrocephalus.

Exclusion criteria for patients were: Infants without hydrocephalus and hydrocephalic infants with complications

\section{Tools of the study:}

All recruited infants were interviewed, assessing history of socio-demographic conditions as maternal and paternal ages, father occupation, consanguinity, 
economic status, onset of prenatal care, geographic location of pregnancy. The questionnaire included history of co morbid conditions as maternal diabetes. Chronic hypertension, pregnancy induced hypertension, preeclampsia, eclampsia, single or multiparous gestation, maternal alcohol, tobacco, drug use, infection, trauma during gestation, trauma or sexually transmitted disease at parturition. Duration of hydrocephalus, type of treatment, patient compliance to treatment, regular check up with physicians, personal home care as home follow up of medical treatment, complications and other family members with hydrocephalus.

\section{Investigations}

Infants group with hydrocephalus underwent the following investigations: $\mathrm{X}$ ray, $\mathrm{CT}$ (computerized topography) and MRI (magnetic resonance imaging). Normal infants were examined to exclude hydrocephalus.

\section{Data collection:}

Data entry was done using Excel program then transferred to SPSS version 20 program, office 2013.

\section{Statistical analysis:}

The data was collected, coded and entered on Microsoft Excel Worksheet. Data was then transferred to SPSS format for data checking, cleaning and lastly analysis of data. The Program used for data analysis is SPSS version 20 for windows.

Descriptive statistics was done for demographic data. The statistical tests used in this study were student $\mathrm{t}$ test; Chi-Square test was used as a significant test. $\mathrm{P}$ value was considered significant when $<0.05$ and regression analysis to calculate odds ratio was. A logistic regression was built to find the risk factors that affect the epidemiology of hydrocephalus.

\section{Ethical consideration}

The study was approved by the Ethical committee of the Faculty of Medicine-

Sohag University. An informed written consent was taken from all participants in the study. All participants were reassured of data confidentiality.

\section{Results}

The studied infants 240 live-born infants with surgically treated infantile hydrocephalus from February 2014 to December 2014 in Sohag University and Insurance hospitals.

Incidence of hydrocephalus calculated of all new cases of hydrocephalus 240 live-born infants with surgically treated infantile hydrocephalus divided by all live births registries in Sohag Governorate(35.500) live births, Incidence was 6.96/1000 live births. In this study of 240 cases of infantile hydrocephalus, Maternal age mean $/ \mathrm{SD}=$ $29 \pm 9$ years, infant age mean $33 / \mathrm{SD}= \pm$ 31 days and period of gestation mean $/ \mathrm{SD}=8.5 \pm 1$ month. There was sex predominance as the female: male ratio was $2: 1$.

In our cross sectional study, several significant risk factors were identified among 240 well defined cases of congenital hydrocephalus. The percentages of risk factors in our study were as follow: uniparity $53.3 \%$, age of the mother $<20$ years at conception $25 \%$, maternal illness especially diabetes $13.8 \%$, fever and common cold $32.1 \%$, exposure to pollutants, irradiation $15.1 \%-13.3 \%$ respectively.( $63.8 \%$ ) of mothers received some drugs (not exactly known) in first 3 months of pregnancy. Consanguineous marriage was present in $58 \%$ of parents of patients and family history of hydrocephalus was detected in $20.8 \%$ of affected families. Mothers 
not received antenatal care (poor) $51.7 \%$, polyhydramnios $(7.5 \%)$, oligohydramnios $(7.1 \%)$, early vaginal bleeding (14.2\%), preeclampsia $(7.5 \%)$, twin pregnancy was recorded in $(7.9 \%)$, breech presentation in $(12.9 \%)$ and delivery by CS was needed by $(40 \%)$ of mothers of infants with hydrocephalus (table 1). Risk factors: low

\section{Discussion}

\section{1-Incidence}

Unusual high incidence (3.76.96/1000) was detected in Egypt and this agree with our results which was 6.96 per 1000 neonates. The incidence is high in some Arabian countries as Algeria 7.5/1000 also among Palestinians 5.49/1000. Also, Spanish have high incidence attributed to Arabian influences and consanguinity. Low incidence in the following countries respectively, Kuwait 1.19/1000, United Arab Emirates 1.14/1000, Bahrain 1.5/1000 and Oman 1.25/1000. Explanation of results recorded from The Gulf Cooperation Council (GCC) countries were mass educational dietetic program emphasized the importance of vegetables and fruit rich in folic acid (9).

\section{2-Risk factors}

The maternal risk factors for congenital malformations especially neurological ones, in a study of Ain Shams University, Egypt, were: maternal illness especially diabetes (7.28\%), fever and common cold $(16.69 \%)$, exposure to pollutants $(58.57 \%)$. Mothers received antenatal care $(31.8 \%)$, received multivitamins and folic acid during pregnancy were (27.5\%). Mothers received some drugs (not exactly known) in first 3 months of pregnancy $(36.32 \%)$. Mothers of infants with Hydrocephalus were more significantly affected $(\mathrm{p}<0.05)$ than controls with polyhydramnios $(10.8 \%)$, oligohydramnios $(9.81 \%)$ and preeclampsia (39.43\%). Twin pregnancy was recorded in $(2.94 \%)$ and breech presentation in $(11.32 \%)$ in this study. Delivery by caesarean section (CS) was needed by $(23.1 \%)$ of mothers of patients with Hydrocephalus. Consanguineous marriage was present in $(45.8 \%)$ of parents of patients and family history of Hydrocephalus was detected in (16.69\%) of affected families, these results agree with our results in Sohag Governorate(10).

\section{Sociodemographic conditions}

Young maternal age carried a higher risk of neural tube defects, as regards father occupation were significantly decreased $(15 \%)$ in this study compared $40 \%$ in the normal group with significant difference. This denotes a higher incidence of hydrocephalus in lower sociodemographic groups (11).

These are at higher risk due to environmental or life style factors. In addition their wives lack access to prenatal care, proper balanced nutrition and intake of vitamins or folic $\operatorname{acid}(12)$.

\section{4-Antenatal care:}

Poor antenatal care as mothers in this study did not receive antenatal care $(51.7 \%)$. This high-lights the importance of measures for health promotion and disease prevention in child bearing-age women with special attention to prenatal care and childbirth which can influence neonatal indicators and prevention of birth defects (13). Multiparty was associated with increased incidence of hydrocephalus in this study $(46.7 \%)$. The risk of mutations in women with 3rd and higher gravida is higher than in women with primary or secondary 
gravida (12). The frequency of hydrocephalus presenting by breech in this study was (13\%). It is well recognized that a foetus presenting by breech is more likely to have the congenital malformations approximately threefold(14). Good antenatal care in this study (48\%) of mothers of patients with hydrocephalus had a positive history of drug intake (not definitely identified) in the first trimester of pregnancy. About 2-3\% of all birth defects result from the use of drugs. The result is under weight, under developed and may be abnormal developed baby (15).

\section{5-Environmental factors}

Mothers in this study were cigarette smokers $(76 \%)$ compared to $(24 \%)$ of normal ( $\mathrm{p}<0.05)$, either actual smokers or passive smokers, i.e., exposed to environmental tobacco smoke. Maternal smoking for one month before conception through the third month of pregnancy (preconception period) was linked with birth defects of the brain, heart, clef lip with or without cleft palate (CLP)(16). Women were exposed to pollutants by working or living near industrial factories, or helping their husbands in cultivating the land where pesticides were aggressively used (76\%). In Egypt there is no specific regulations regarding the use of pesticides (type, amount) and there is no considerable awareness about possible related health problems including hydrocephalus (17).

\section{6-Importance of vitamins and folic acid}

Mothers received folic acid or multivitamin (76\%) were which is significantly lower than that in the normal group. Vitamin B12 might also confer health benefits, however such benefits are difficult to ascertain because of the complementary functions of vitamin B12 and folic acid, so foods have to be fortified with vitamin B12 in addition to the current mandatory folic acid fortification of grains(18).

\section{Conclusions \& Recommendations:}

1-Health education as regards risk factors were: uniparity, young maternal age, exposure to irradiation, contact with infectious agents, smoking, drug intake, twins, maternal diabetes, consanguinity, low sociodemographic conditions congenital malformations than a foetus with cephalic presentations, the abnormality is approximately threefold (14). We found a higher frequency of Hydrocephalus in the offspring of mothers having pre-eclampsia $(8 \%)$ compared to normal. The incidence of major congenital anomalies in infants of diabetic mothers was (11\%) 5 times higher than and positive family history of hydrocephalus must be voided.

1-Folic acid supplementation. The recommended daily dose of folic acid for reduction of risk of hydrocephalus in women with no previous affected pregnancies is $0.4 \mathrm{mg}$.

2-Surveys of hydrocephalus must be done in every country and even in different regions of same country to provide prevalence of hydrocephalus, pattern of occurrence, nature, identify causes and associated risk factors and ultimately to prevent or reduce the occurrence of hydrocephalus that responsible for infant mortality rate under 5 years $(23.8 / 1000)$ and neonatal mortality rate $(15.3 / 1000)$ in Sohag Governorate.

3-Prenatal diagnosis and screening programs to prevent these severe, costly, often deadly defects must to be planned in our locality.

4- Further researches are recommended to confirm the actual risk factors which contribute to hydrocephalus in our locality pattern 
(of occurrence, nature, identify causes and associated risk factors, prenatal diagnosis and screening programs to prevent these severe, costly, often deadly defects to conclude, hydrocephalus continues to be an important cause of morbidity and mortality in infants including Egypt.

\section{References}

1) Boltshauser E, Schneider J, Kollias S, Waibel P, Weissert $M$. Vanishing cerebellum hydrocephalus Eur J Paediatr Neurol 2002;6:109137).

2) Bowman RM, McLone DG, Grant JA, Tomita T, Ito JA. Hydrocephalus outcome: a 25-year prospective. Pediatr Neurosurg 2001; 34:114-205)

3) Cinalli G, Spennato P, Savarese $L$, Ruggiero C, Aliberti F, Cuomo L, Cianciulli E, Maggi G. Endoscopic aqueductoplasty and placement of a stent in the cerebral aqueduct in the management of isolated fourth ventricle in infants. J Neurosurg 2006; 104 (Suppl):21-7.

4)Cochrane DD, Kestle JR. The influence of surgical operative experience on the duration of first ventriculoperitoneal shunt function and infection. Pediatr Neurosurg

5)E Fernell, G Hagberg, B Hagberg. Infantile hydrocephalus epidemiology: an indicator of enhanced survival2001; 285:2981-6.Archives of Disease in Childhood 1994; 70: F123-F128

2003; 38:295-301.

6) Enger PO, Svendsen F, Wester K. CSF shunt inections in infants: experiences from apopulation-based study. Acta Neurochir (Wien) 2003; 145:243-8; discussion 248.

7)Honein MA, 2)Paulozzi LJ, Mathews TJ, Erickson JD, Wong LY. Impact of folic acid fortification of the US food supply on the occurrence of neural tube defects. Jama.

8)Kao CL, YangTF, WongTT, Cheng LY, Huang SY. Chen HS, Kao CL, Chan RC. The outcome of shunted hydrocephalic children. ZhonghuaYiXueZaZhi(taipei)2001;64: 47-53.

9) Kay H. New Method of assessing visual acuity with pictures. $\mathrm{Br} \mathrm{J}$. Environmental factors in congenital hydrocephalus. 1983; 67:131-133

10) Kestle J, Cochrane D, Alisharan

R. The initial treatment of hydrocephalus: an assessment of surgeons' preference between third ventriculostomy and shunt insertion. NeurolRes 2000; 22:65-8.

11)Kim SK, Wang KC, Cho BK. Surgical outcome of pediatric hydrocephalus treated by endoscopic III ventriculostomy: prognostic factors and interpretation of postoperative neuroimaging. Childs Nerv Syst 2000;161-8; discussion169.

12) Lindquist B, Carlsson G, Persson EK, Uvebrant $P$. Learning disabilities in a population based group of infants with hydrocephalus. Acta Paediatr 2005; 94:878-83.

13) Navarro $R$, Gil-Parra $R$, Reitman AJ, Olavarria G, Grant JA, Tomita T. Endoscopic third ventriculostomy in infants: early and late complications and their avoidance. Childs. Nerv Syst 2006; 22:506-13.

14) Norrlin $S$, Strinnholm $M$, Carlsson M, Dahl M. Factors of significance for mobility in infants with congenital hydrocephalus. Acta Paediatr 2003; 92:204-10

15) Mustafa A. Salih, Waleed R. Murshid, Mohammed Z.Seidahmed. Epidemiology, prenatal management, and prevention of congenital hydrocephalus.Saudi Med J 2014; vol.35 Supplement 1:S 15-S28.

16) Persson EK, Hagberg G, Uvebrant P. Hydrocephalus prevalence and outcome in a population-based cohort of infants born in 1989-1998. Acta Paediatr 2005; 94:726-32. 
17) Rabah M. Shawky a,*, Doaa I. Sadik: Congenital malformations prevalent among Egyptian infants and associated risk factors. The Egyptian Journal of Medical Human Genetics (2011) 12, 69-78.

18) Scarrow AM, Levy EI, Pascucci L, Albright AL. Outcome analysis of
endoscopicIII ventriculostomy. Childs Nerv Syst 2000;16:442-4; discussion445

19) Stephensen $H$, Tisell $M$, Wikkelsö C. There is no transmittal pressure gradient in communicating or non communicating hydrocephalus. Neurosurgery $\quad 2002 ; \quad 50: 763-71$; discussion 771-3. 
Table (1.1) Sociodemographic characteristics and risk factors of the studied hydrocephalic infants

\begin{tabular}{|c|c|c|c|}
\hline \multicolumn{2}{|l|}{ Variable } & $\begin{array}{l}\text { Number of } \\
\text { cases(No) }\end{array}$ & Percent $(\%)$ \\
\hline \multicolumn{4}{|c|}{ Infant's characteristics } \\
\hline \multirow[t]{2}{*}{ Disease } & Hydrocephalus & 240 & \\
\hline & Normal & 600 & \\
\hline \multirow[t]{3}{*}{ Age (in days) } & Mean & 33.392 & \\
\hline & SD & 31.237 & \\
\hline & Range & $1-150$ & \\
\hline \multirow[t]{2}{*}{ Residence } & Rural & 200 & 80 \\
\hline & Urban & 40 & 20 \\
\hline \multicolumn{4}{|c|}{ Maternal risk factors } \\
\hline \multirow{3}{*}{$\begin{array}{l}\text { Maternal age (in } \\
\text { years) }\end{array}$} & Mean & 28.625 & \\
\hline & SD & 8.735 & \\
\hline & Range & $18-50$ & \\
\hline \multirow{2}{*}{$\begin{array}{l}\begin{array}{l}\text { Mother age }<20 \\
\text { years }\end{array} \\
\end{array}$} & Yes & 60 & 25 \\
\hline & No & 180 & 75 \\
\hline \multirow[t]{2}{*}{ Parity } & Unipara & 128 & 53.3 \\
\hline & Multipara & 112 & 46.7 \\
\hline DM & & 33 & 13.8 \\
\hline Fever & & 77 & 32.1 \\
\hline $\begin{array}{ll}\begin{array}{l}\text { Exposure } \\
\text { irradiation }\end{array} & \text { to } \\
\end{array}$ & & 32 & 13.3 \\
\hline \multicolumn{2}{|c|}{ Contact with infectious case } & 37 & 15.4 \\
\hline \multirow[t]{3}{*}{ Smoking } & Active & 2 & 0.8 \\
\hline & Passive & 180 & 75 \\
\hline & Non & 58 & 24.2 \\
\hline Drug intake & & 153 & 63.8 \\
\hline $\begin{array}{l}\text { Contact } \\
\text { pollutant }\end{array}$ & & 37 & 15.4 \\
\hline \multicolumn{4}{|l|}{ Family risk factors } \\
\hline Consanguinity & & 138 & 57.5 \\
\hline Family history & & 50 & 20.8 \\
\hline \multicolumn{4}{|c|}{ Paternal risk factors } \\
\hline \multirow{2}{*}{ Age of the father } & $<50$ years & 167 & 69.6 \\
\hline & $>50$ years & 73 & 30.4 \\
\hline \multirow{3}{*}{$\begin{array}{l}\text { Period of gestation } \\
\text { (in months) }\end{array}$} & Mean & 8.563 & \\
\hline & SD & 0.706 & \\
\hline & Range & $7-9.5$ & \\
\hline
\end{tabular}


Table (1.2) Sociodemographic characteristics and risk factors of the studied hydrocephalic infants

\begin{tabular}{|c|c|c|c|}
\hline Variable & & $\begin{array}{ll}\begin{array}{l}\text { Number } \\
\text { cases(No) }\end{array} & \text { of } \\
\end{array}$ & Percent (\%) \\
\hline \multirow[t]{2}{*}{ Antenatal care } & Good & 116 & 48.3 \\
\hline & Poor & 124 & 51.7 \\
\hline \multicolumn{2}{|c|}{ Previous abortion or stillbirth } & 64 & 26.7 \\
\hline Preeclampsia & & 18 & 7.5 \\
\hline \multirow[t]{3}{*}{ Amniotic fluid } & Normal & 205 & 85.4 \\
\hline & Polyhydramnios & 18 & 7.5 \\
\hline & Oligohydramnios & 17 & 7.1 \\
\hline \multirow[t]{2}{*}{ Vaginal bleeding } & No & 204 & 85.8 \\
\hline & yes & 36 & 14.2 \\
\hline Twin delivery & & 19 & 7.9 \\
\hline \multirow{3}{*}{$\begin{array}{l}\text { Mode } \\
\text { presentation }\end{array}$} & Vertex & 192 & 80 \\
\hline & Transverse & 17 & 7.1 \\
\hline & Breech & 32 & 12.9 \\
\hline \multirow[t]{2}{*}{ Delivery } & Normal & 144 & 60 \\
\hline & Cesarean section & 96 & 40 \\
\hline
\end{tabular}


Magda Mohamed Ali, et al

Epidemiological study of Congenital Hydrocephalus

Table (2.1) Distribution of the studied hydrocephalic infants according to Sociodemographic characteristics and risk factors

\begin{tabular}{|c|c|c|c|c|c|}
\hline \multicolumn{2}{|c|}{ Variable } & hydrocephalus & normal & \multirow[t]{2}{*}{ Chi square } & \multirow[t]{2}{*}{ P value } \\
\hline \multicolumn{4}{|c|}{ Infant's characteristics } & & \\
\hline Number of infants & & 250 & 600 & & \\
\hline \multirow[t]{3}{*}{ Age (in months) } & Mean & 3.392 & 14.150 & t test & $0.02(\mathrm{~S})$ \\
\hline & SD & 2.237 & $\begin{array}{c}25.97 \\
3\end{array}$ & 1.290 & \\
\hline & Range & $1-6$ & $1-36$ & & \\
\hline \multicolumn{4}{|c|}{ Maternal risk factors } & & \\
\hline \multirow[t]{3}{*}{$\begin{array}{c}\text { Maternal age (in } \\
\text { years) }\end{array}$} & Mean & 22.625 & 33.930 & t test & $\begin{array}{l}<0.001 \\
(\mathrm{HS})\end{array}$ \\
\hline & SD & 8.735 & 4.928 & 4.934 & \\
\hline & Range & 15-39 & 25-39 & & \\
\hline \multirow{2}{*}{$\begin{array}{c}\text { Mother age }<20 \\
\text { years }\end{array}$} & Yes & 60 & 53 & 20.372 & \multirow{2}{*}{$\begin{array}{c}<0.001 \\
\text { (HS) }\end{array}$} \\
\hline & No & 180 & 547 & & \\
\hline \multirow[t]{2}{*}{ Parity } & $\begin{array}{l}\text { Unipara/ } \\
\text { nullipara }\end{array}$ & 90 & 345 & 3.915 & \multirow[t]{2}{*}{$0.048(\mathrm{~S})$} \\
\hline & Multipara & 150 & 255 & & \\
\hline DM & & 33 & 78 & 4.175 & $0.041(S)$ \\
\hline Fever & & 77 & 286 & 3.477 & $0.02(S)$ \\
\hline $\begin{array}{l}\text { Exposure to } \\
\text { irradiation }\end{array}$ & & 32 & 26 & 10.074 & $0.002(\mathrm{~S})$ \\
\hline \multicolumn{2}{|c|}{ Contact with infectious case } & 37 & 91 & 4.438 & $0.035(\mathrm{~S})$ \\
\hline \multirow[t]{3}{*}{ Smoking } & Active & 2 & 6 & 9.870 & $0.007(\mathrm{~S})$ \\
\hline & Passive & 180 & 154 & & \\
\hline & Non & 58 & 320 & & \\
\hline Drug intake & & 153 & 320 & 4.071 & $\begin{array}{c}\mathbf{0 . 0 4 4} \\
(\mathrm{S})\end{array}$ \\
\hline $\begin{array}{c}\text { Contact with } \\
\text { pollutant }\end{array}$ & & 37 & 169 & 0.329 & $\begin{array}{l}0.566 \\
(\mathrm{NS})\end{array}$ \\
\hline \multicolumn{4}{|c|}{ Family risk factors } & & \\
\hline Consanguinity & & 138 & 77 & 22.941 & $\begin{array}{l}<0.001 \\
(\text { HS })\end{array}$ \\
\hline Family history & & 50 & 78 & 11.289 & $\begin{array}{c}\mathbf{0 . 0 0 1} \\
(\mathrm{S})\end{array}$ \\
\hline \multirow[t]{2}{*}{ Age of the father } & $<50$ years & 167 & 540 & 11.332 & $\begin{array}{c}\mathbf{0 . 0 0 1} \\
(\mathrm{S})\end{array}$ \\
\hline & $>50$ years & 73 & 160 & & \\
\hline
\end{tabular}

$* \mathbf{P}<0.05$ significant $* * \mathbf{P}<0.01$ highly significant 
Table (2.2) Distribution of the studied hydrocephalic infants according to Sociodemographic characteristics and risk factors

\begin{tabular}{|c|c|c|c|c|c|}
\hline \multicolumn{2}{|c|}{ Variable } & hydrocephalus & normal & $\begin{array}{c}\text { Chi } \\
\text { square }\end{array}$ & P value \\
\hline \multicolumn{6}{|c|}{$\begin{array}{l}\text { Pregnancy and labor risk factors } \\
\end{array}$} \\
\hline \multirow{3}{*}{$\begin{array}{l}\text { Period of gestation } \\
\quad \text { (in months) }\end{array}$} & Mean & 8.563 & 8.605 & t test & $0.01(\mathrm{~S})$ \\
\hline & SD & 0.706 & 0.686 & 0.510 & \\
\hline & Range & $6-9$ & $8.5-9.5$ & & \\
\hline \multirow[t]{2}{*}{ Antenatal care } & Good & 116 & 493 & 4.637 & $0.05(\mathrm{~S})$ \\
\hline & poor & 124 & 107 & & \\
\hline \multicolumn{2}{|c|}{ Previous abortion or stillbirth } & 64 & 128 & 3.635 & $\begin{array}{c}0.057 \\
(\mathrm{NS}) \\
\end{array}$ \\
\hline Preeclampsia & & 18 & 51 & 2.467 & $0.01(\mathrm{~S})$ \\
\hline \multirow{3}{*}{ Amniotic fluid } & Normal & 205 & 510 & 2.690 & $0.05(\mathrm{~S})$ \\
\hline & $\begin{array}{c}\text { Polyhydramni } \\
\text { os }\end{array}$ & 18 & 36 & & \\
\hline & $\begin{array}{c}\text { Oligohydramn } \\
\text { ios }\end{array}$ & 17 & 54 & & \\
\hline \multirow[t]{2}{*}{ Vaginal bleeding } & No & 204 & 525 & 0.616 & $\begin{array}{c}0.432 \\
(\mathrm{NS})\end{array}$ \\
\hline & Yes & 36 & 75 & & \\
\hline Twin delivery & & 19 & 30 & 0.915 & $0.03(\mathrm{~S})$ \\
\hline \multirow[t]{3}{*}{$\begin{array}{c}\text { Mode of } \\
\text { presentation }\end{array}$} & Vertex & 192 & 428 & 1.705 & $\begin{array}{c}0.426 \\
(\mathrm{NS})\end{array}$ \\
\hline & Transverse & 17 & 65 & & \\
\hline & Breech & 31 & 107 & & \\
\hline \multirow[t]{2}{*}{ Delivery } & vaginal & 144 & 492 & 6.014 & $\begin{array}{c}0.014 \\
(\mathrm{~S})\end{array}$ \\
\hline & $\begin{array}{c}\text { Cesarean } \\
\text { section }\end{array}$ & 96 & 108 & & \\
\hline
\end{tabular}


Table (3) Multivariate logistic regression analysis of risk factors which approved to be significant by univariate logistic regression analysis

\begin{tabular}{|c|c|c|c|c|c|c|c|}
\hline Variables & & & & & \multicolumn{2}{|c|}{ Odd's } & \multicolumn{2}{|c|}{ 95\% C.I.for EXP(B) } \\
\cline { 5 - 7 } & B & S.E. & Wald & Sig. & Ratio & Lower & Upper \\
\hline Sex(male) & -0.010 & 0.010 & 0.998 & 0.03 & 1.990 & 0.971 & 1.010 \\
Mother age & 5.722 & 1.758 & 10.593 & 0.001 & 305.421 & 9.738 & 9579.000 \\
Parity & 0.691 & 0.660 & 1.096 & 0.295 & 0.995 & 0.548 & 7.271 \\
DM & 2.988 & 1.024 & 8.524 & 0.004 & 19.855 & 2.670 & 147.625 \\
Fever & 1.316 & 0.669 & 3.870 & 0.049 & 3.728 & 1.005 & 13.833 \\
Exposure to & 2.076 & 1.183 & 3.078 & 0.039 & 7.970 & 0.784 & 81.019 \\
irradiation & & & & & & & \\
Contact with & 0.107 & 1.027 & 0.011 & 0.917 & 1.113 & 0.149 & 8.338 \\
infectious case & & & & & & & \\
Smoking & 0.196 & 1.728 & 0.113 & 0.021 & 1.843 & 0.191 & 3.714 \\
Drug intake & -0.474 & 0.795 & 0.356 & 0.05 & 1.622 & 0.131 & 2.957 \\
Pollutant contact & 0.051 & 0.643 & 0.006 & 0.937 & 1.052 & 0.298 & 3.711 \\
Consanguinity & 0.919 & 0.528 & 3.036 & 0.018 & 2.508 & 1.892 & 7.053 \\
FH & 2.357 & 0.850 & 7.684 & 0.006 & 10.560 & 1.995 & 55.907 \\
Age of father & 1.720 & 0.663 & 6.742 & 0.009 & 5.587 & 1.525 & 20.474 \\
Antenatal care & 3.286 & 1.354 & 5.891 & 0.015 & 26.747 & 1.883 & 380.033 \\
Abortion or stillbirth & -0.398 & 0.740 & 0.289 & 0.591 & 0.672 & 0.157 & 2.865 \\
Preeclampsia & 1.223 & 1.505 & 0.660 & 0.016 & 3.398 & 0.178 & 64.943 \\
Amniotic fluid & -2.411 & 1.693 & 2.028 & 0.154 & 0.090 & 0.003 & 2.478 \\
Vaginal bleeding & 0.941 & 0.892 & 1.114 & 0.291 & 0.563 & 0.446 & 14.716 \\
Twin delivery & 1.171 & 0.922 & 1.613 & 0.204 & 3.225 & 0.529 & 19.656 \\
Period of gestation & -0.325 & 0.443 & 0.539 & 0.003 & 3.722 & 0.303 & 1.721 \\
Mode of presentation & -1.386 & 1.512 & 0.840 & 0.359 & 0.250 & 0.013 & 4.844 \\
Mode of Delivery & 1.538 & 0.530 & 8.402 & 0.004 & 4.653 & 1.645 & 13.160 \\
Constant & -18.482 & 6.477 & 8.144 & 0.004 & 0.000 & & \\
\hline
\end{tabular}




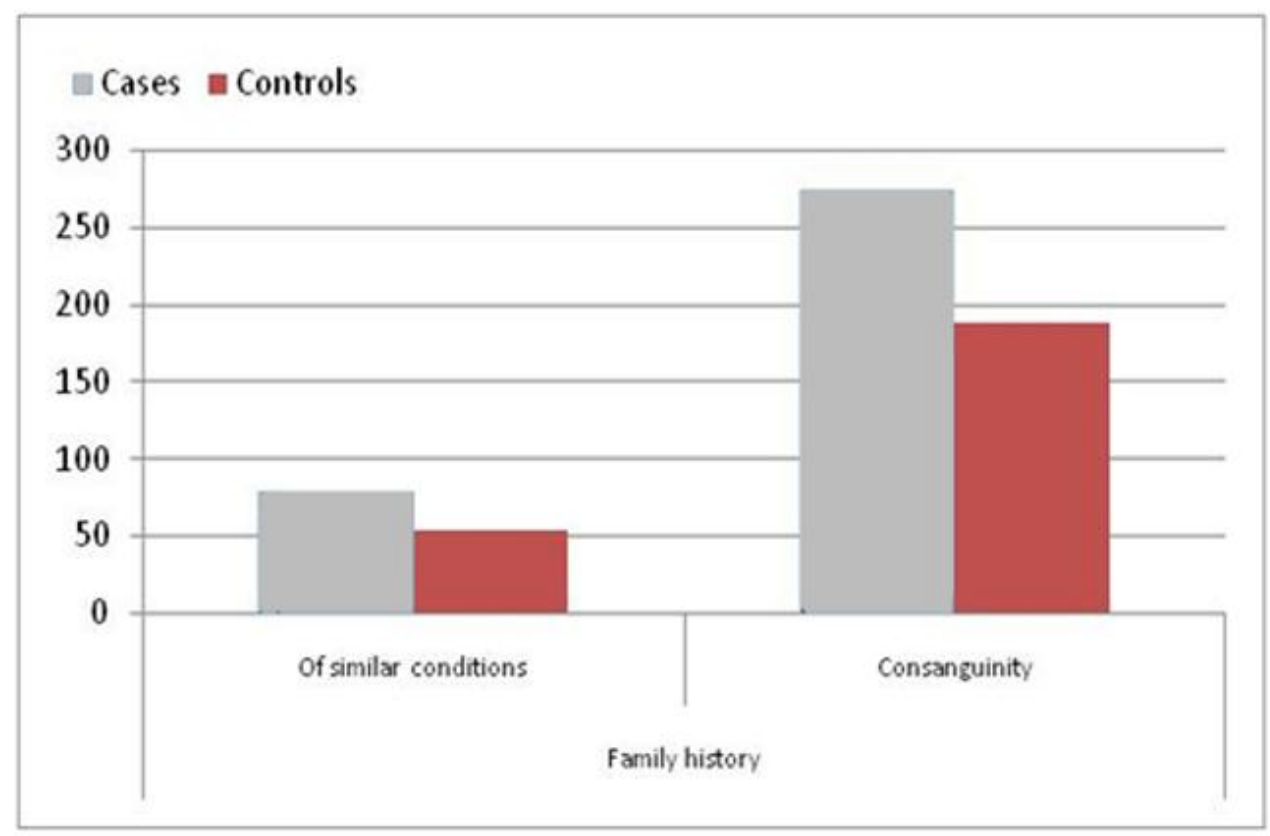

Figure (1); shows the relationship of family history to occurrence of congenital hydrocephalus

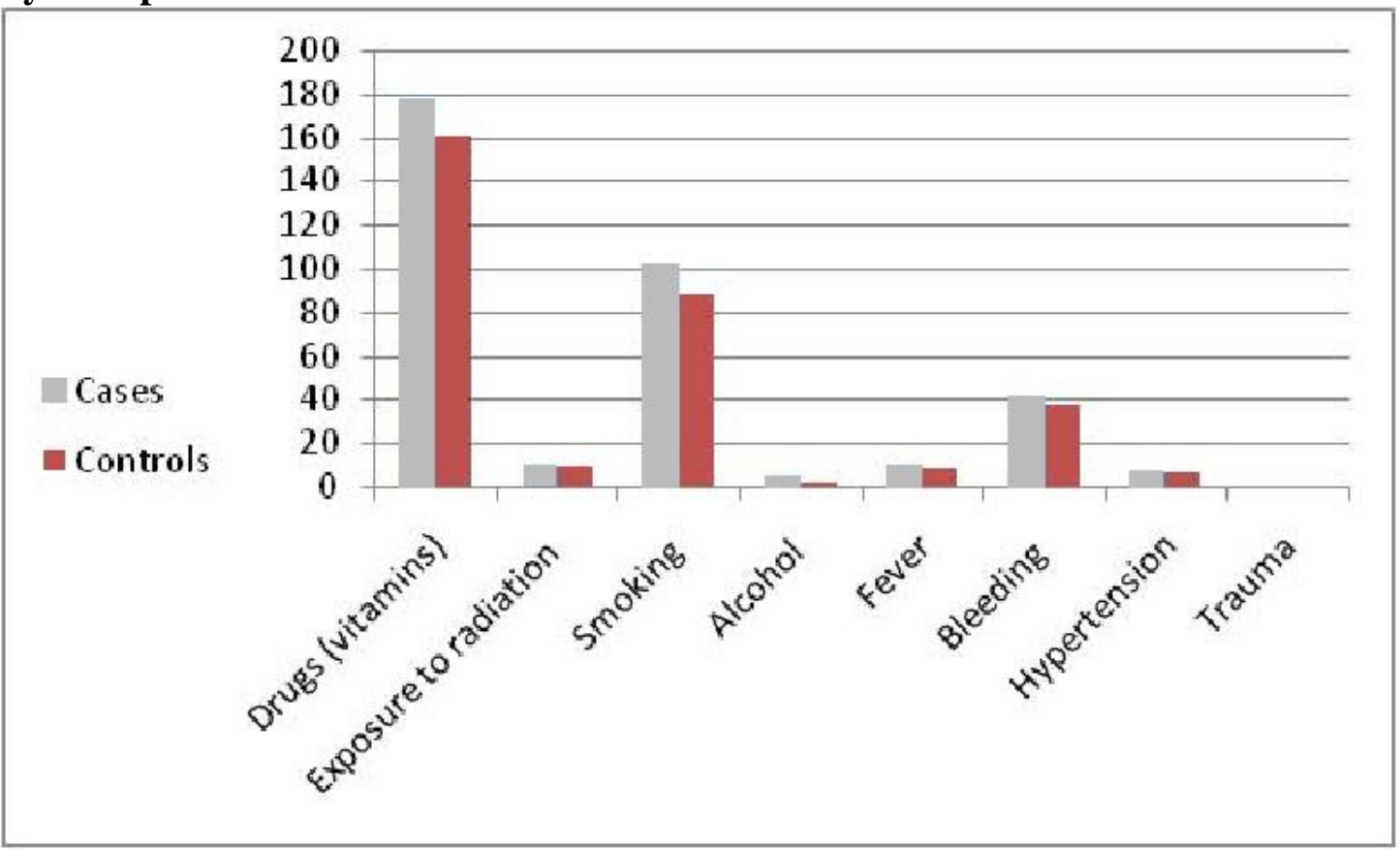

Figure (2); shows the relationship of risk factors to occurrence of congenital hydrocephalus. 